Culture et histoire dans l'espace roman

$6 \mid 2011$

Figures du pouvoir dans la littérature hispanoaméricaine

\title{
La mafia intelectual en El miedo a los animales de Enrique Serna
}

Marie-Pierre Ramouche

\section{OpenEdition}

Journals

Edición electrónica

URL: https://journals.openedition.org/cher/9692

DOI: $10.4000 /$ cher.9692

ISSN: 2803-5992

\section{Editor}

Presses universitaires de Strasbourg

\section{Edición impresa}

Fecha de publicación: 30 junio 2011

Paginación: 137-147

ISBN: 978-2-35410-033-9

ISSN: 1968-035X

Referencia electrónica

Marie-Pierre Ramouche, «La mafia intelectual en El miedo a los animales de Enrique Serna»,

reCHERches [En línea], 6 | 2011, Publicado el 17 diciembre 2021, consultado el 26 enero 2022. URL:

http://journals.openedition.org/cher/9692 ; DOI: https://doi.org/10.4000/cher.9692

\section{cc) (ㅇ) (-)}

Ce(tte) œuvre est mise à disposition selon les termes de la Licence Creative Commons Attribution -

Pas d'Utilisation Commerciale - Partage dans les Mêmes Conditions 4.0 International. 


\title{
La mafia intelectual en El miedo a los animales de Enrique Serna
}

\author{
Marie-PierRe Ramouche \\ Université de Perpignan
}

Erente a los abusos del poder político, el intelectual hispanoamericano, el
escritor en particular, quiso verse a sí mismo, durante décadas, como «la voz de los sin voz», o sea la encarnación de la resistencia frente al poder. En los años 1950-1960, momento álgido de este ímpetu revolucionario, surge el prototipo del intelectual comprometido dispuesto a hacer de su literatura un arma de combate para cambiar el mundo. Algunas décadas más tarde, con "el fin de la historia», el de las ideologías y la vuelta a la paz democrática en la mayor parte de los países hispanoamericanos, las últimas generaciones de escritores ya no se sienten portadores de la misma misión. Asistieron al proceso de autocrítica de la intelligentsia de izquierdas y las lecciones del pasado parecen incitarles a considerar su papel frente al poder con mucho más escepticismo.

Este cuestionamiento del estatus del intelectual es el meollo de la novela El miedo a los animales del escritor mexicano Enrique Serna. La novela fue publicada en 1995, al salir del sexenio del controvertido presidente Carlos Salinas de Gortari, un periodo muy ambiguo en las relaciones entre el poder político y los intelectuales. Sin duda estas circunstancias explican en parte el tema de esta novela que se puede considerar como un verdadero panfleto contra el establishment intelectual mexicano. En esta obra, Serna se dio a la tarea de desmitificar de la manera más corrosiva posible a los miembros de su «casta». Oponiéndoles al poder, su enemigo consagrado, el autor quiso 
demostrar que los intelectuales se parecen mucho más de lo que se cree a los que combaten.

La virulenta diatriba anti-intelectual de El miedo a los animales cobra un sentido peculiar en el contexto mexicano en que los letrados gozan de un prestigio muy especial y tienen, por lo tanto, relaciones más que ambiguas con el poder político.

\section{Los intelectuales mexicanos frente al poder}

En su obra dedicada a los letrados mexicanos, Philippe Ollé-Laprune subraya el aura casi sagrada que envuelve la figura del escritor y de su saber en este país:

Au Mexique, la relation à l'écriture est empreinte de religiosité; il y a une forme d'absolu qui touche le livre et lui donne une résonance particulière. Surtout auprès de la grande majorité de la population qui ne lit rien, mais a de façon diffuse le respect des clercs, de ceux qui savent déchiffrer (OlléLaprune 2008: 45).

El reciente homenaje (noviembre de 2008) que el país entero organizó en honor a los ochenta años de Carlos Fuentes - con innumerables conferencias, un simposio, una ópera, un ciclo de cine e incluso la instauración del «Día nacional de lectura de la obra de Carlos Fuentes» - no podría ser más explícito en cuanto al respeto, por no decir la veneración, de los mexicanos por sus maestros. Es posible que el prestigio del que gozan siga siendo consecuencia de la ausencia de una sociedad civil fuerte que la existencia de los intelectuales mitiga en parte. Pero tal influencia se vuelve paradójica cuando se considera que México es un país en el que casi nadie lee: en Escritores y poder, Xavier Ledesma explica que, de promedio, cada mexicano lee 0,5 libro al año y que en América Latina, sólo Haití se encuentra en una situación peor que la de México... (Rodríguez Ledesma 2001: 54).

Esta importancia otorgada a los intelectuales puede ser de doble filo cuando se exagera en exceso y se acaba por diabolizarlos, como pudo ser el caso en la últimas décadas, por parte tanto del gobierno como del gremio intelectual.

Podemos recordar, por ejemplo, el escándalo que causó la novela $L a$ Mafia (1967) entre el mundillo intelectual mexicano. En esta obra, el escritor argentino Luis Guillermo Piazza acusa a todos los colaboradores de $\mathrm{La}$ cultura en México (reconocido suplemento literario de la revista Siempre!), entre los cuales se encuentran entonces Carlos Fuentes, Carlos Monsiváis, 
José Luis Cuevas, José Emilio Pacheco, Vicente Leñero, etc., de monopolizar el debate literario excluyendo a cualquier persona ajena a su "Mafia». Expresión de un fantasma o realidad, la novela de Piazza participó en el anclaje de una leyenda intelectual «mafiosa» en el imaginario nacional.

En cuanto a las reacciones del poder, podemos observar dos actitudes frente a los intelectuales: represión o captación. En las últimas décadas del siglo XX, presidentes como Díaz Ordaz o López Portillo, escogieron la vía represiva, encarcelando a los intelectuales molestos (a José Revueltas después de la masacre de Tlatelolco), difamándolos (Elena Garro) o censurándolos (Julio Scherer).

Otros, como Echeverría o Salinas de Gortari prefirieron un método más maquiavélico y trataron de seducir y mimar a estos adversarios potentes. Carlos Salinas de Gortari (presidente del país de 1988 a 1994), por ejemplo, para hacer olvidar el fraude escandaloso con el que ganó las elecciones contra Cuauhtémoc Cárdenas, aumentó fuertemente el presupuesto dedicado a la cultura, creó el CONACULTA (Consejo Nacional para la Cultura y las Artes, equivalente al ministerio de cultura del país) y financió un generosísimo sistema de becas, en algunos casos vitalicias, único en el mundo (Volpi, 2004: 192). Esta estrategia dio sus frutos ya que acabó granjeándose la simpatía de la casi totalidad de los intelectuales de la época entre los cuales Octavio Paz, Enrique Krauze, Carlos Fuentes y Héctor Aguilar Camín. Aguilar Camín hasta se convirtió en un cercano colaborador del presidente y acabó por declarar, a pesar de la existencia de pruebas irrefutables, que las elecciones de 1988 habían sido ganadas de manera completamente legal por Salinas de Gortari.

El mandato de Salinas de Gortari, más que revelador acerca de las ambigüedades relacionales entre el poder y el saber, es precisamente el periodo escogido por Serna para ambientar su novela. Contemporáneo de estos sucesos y en tanto que intelectual, Serna reflexionó sobre el lugar ocupado por los intelectuales en su país a través de numerosos artículos, (reunidos en el libro Las caricaturas me hacen llorar). Otros varios escritores trabajaron sobre el tema. Podemos citar, a pesar de lo paradójico que pueda parecer cuando se conocen sus ambiguas relaciones con el poder, a Enrique Krauze (Caudillos culturales de la revolución), Héctor Aguilar Camín (Morir en el golfo; La guerra de Galio), o más recientemente a Jorge Volpi y sus varios ensayos y novelas que ofrecen una reflexión sobre los estrechos vínculos entre saber y poder. Se ve pues que este tema es ampliamente debatido en las letras mexicanas. Lo que nos interesa particularmente en esta 
novela de Serna es que el cuestionamiento crítico roza el paroxismo. El autor nos ofrece, en el linaje de novelas como Bouvard et Pécuchet o Les illusions perdues, una caricatura disolvente del mundillo intelectual mexicano y hace pedazos el halo dorado que detentan en su país. Al seguir los pasos de Evaristo Reyes, el protagonista de El Miedo a los animales, el lector se va dando cuenta de que el poder, en lo más negativo de su esencia, es también atributo de los letrados.

\section{El miedo a los animales, panfleto antiintelectual}

\section{La perversión de Evaristo Reyes}

El miedo a los animales cuenta la historia de Evaristo Reyes, ex periodista cándido que acaba trabajando como agente de la policía judicial, o sea, la peor, menos recomendable, más vil de las instituciones que representan el poder en México. Este descenso al infierno es la historia de una gran perversión.

Mientras se sentía frustrado en su trabajo como periodista mal pagado, Evaristo, aún joven, lleno de ilusiones y de anhelos de justicia social, piensa haber encontrado una manera infalible para escribir el reportaje de su vida: entrar en la policía judicial con el fin de estudiar, desde el interior, los mecanismos de corrupción que infectan el conjunto del sistema. La novela comienza pues por describir los oscuros bastidores de la policía mexicana cuyos innumerables defectos parecen condensados en la piel del jefe de Evaristo, el comandante Jesús Mayortena. El físico repugnante del comandante "rostro verdusco y garapiñado por la viruela", "ojillos pardos», "nariz curvada hacia adentro y una boca mezquina, casi una ranura sin labios» (Serna 2005: 11) no es sino el pálido reflejo de los vicios que corroen interiormente a ese policía criminal, corrupto, violento, grosero, inculto, alcohólico, drogadicto $y$, además, homosexual reprimido ${ }^{1}$. Evaristo da sus primeros pasos en el medio bajo el ala de Mayortena y, como lo escribe el narrador, las historias que comienza a acumular para su reportaje "podrían haber inaugurado la vertiente criminal del realismo mágico» (Serna 2005: 21).

1 El comandante escoge a jóvenes travestis como sus «novias» fingiendo no darse cuenta de que son hombres y obliga a todos sus subalternos a seguirle el juego y tratar con extrema galantería a sus "queridas», siendo el menor comentario sinónimo de muerte inmediata. 
Pero el famoso reportaje no sale a la luz pues poco a poco Evaristo se prenda de las ventajas financieras derivadas de este oficio y los fajos de billetes le hacen olvidar su cuaderno de notas, matriz de su futura novela. El tiempo corre y Evaristo sigue trabajando al servicio de Mayortena pero siendo continuamente humillado por este último. Por sus cualidades literarias sus compañeros le ponen el apodo peyorativo de «intelectual» y le encargan la redacción fastidiosa de todos los informes en los cuales, dicho sea de paso, tiene que dar prueba de mucha imaginación y de proezas estilísticas para disfrazar las fechorías de su superior de acciones honestas y útiles para la seguridad pública.

Evaristo no es pues ni un buen y valeroso escritor, ni « un buen madero malo "; el balance de su vida es espantoso: divorciado, corrupto, alcohólico, drogadicto, él mismo se abalanzó en un proceso de autodestrucción. Evaristo pensaba ser lo suficiente fuerte y sólido para acercarse al poder pero su sed de saber le valió, igual que a Fausto, la damnación. No pudo resistir las tentaciones de Mefistófeles y perdió su alma.

En la novela, la historia de esta perversión se condensa entera en el primer capítulo. No es pues lo esencial de la novela; lo que interesa verdaderamente a Serna es mostrar que Evaristo, intelectual fallido convertido en su peor enemigo, no es nada diferente de la crème de la crème intelectual del «Todo México", del conjunto de los intelectuales patentados y venerados por la sociedad mexicana.

\section{El intelectual y el policía: dos caras de una misma moneda}

Un elemento va a permitir a Evaristo llevar a cabo una investigación que esta vez le hará descubrir las cloacas de la intelligentsia mexicana. El comandante Mayortena le confía un día la misión de investigar a un periodista llamado Roberto Lima de quien leyó, por casualidad, un artículo en los baños de un chirringuito mientras estaba a punto de encontrarle una utilización mucho más práctica e higiénica a dicho trozo de periódico. El artículo se presentaba como una común y corriente crítica artística pero el periodista había reemplazado algunos títulos de obras por insultos al presidente. Como intelectual de la pandilla, le corresponde a Evaristo encontrar la dirección del tal Roberto Lima. Evaristo entiende que la intención de Mayortena es moler a palos al periodista pero por primera vez desde que está al servicio del comandante, decide desobedecerle. 
El hecho es que Roberto Lima tocó una cuerda sensible en el protagonista pues lo ve como el ser valiente en el que le hubiera gustado transformarse, un ser «capaz de gritarle al poder: ¡Yo también existo!» (Serna 2005: 33). Decide pues ayudarle dándole dinero así como su propia arma para que pueda dejar el país cuanto antes. Y el plan funciona: aquel acto de valentía lo reconcilia consigo mismo y le da la impresión de poder partir de cero otra vez. Desgraciadamente, el sueño de Evaristo es efímero. Al día siguiente se entera de que Roberto Lima ha sido asesinado y comprende que él es el sospechoso idóneo. Si Lima no hubiera sido un intelectual, no hubiera sido tan grave ya que el asesinato hubiera podido ser maquillado como de costumbre sin que nadie se tomara la molestia de investigar más; pero tratándose de un intelecual, o sea de un "intocable", sabe que las cosas irán a más. Ello lo obliga a llevar su propia investigación no entre la policía judicial, por una vez inocente, sino entre el mundo intelectual en que Lima tenía muchos enemigos. Comienza así a infiltrarse en las redes de la sociedad cultural de la capital haciéndose pasar por un intelectual, igual que se había hecho pasar por un policía para acceder al poder judicial.

Pero, a diferencia de su primera investigación en la que descubrió la corrupción que esperaba, estas investigaciones en el traspatio del mundo del saber van a sorprenderle negativamente. A medida que va penetrando los diferentes estratos de este universo, se da cuenta que reinan en él hipocresía, vanidad, dinero, clientelismo. Un sistema comparativo se instaura entonces entre el mundo del saber y el mundo del poder y deja ver que los intelectuales son tanto o más corruptos y viciados que los más viles representantes del poder. La novela se convierte en un libelo contra el conjunto del establishment cultural mexicano, pasando la criba a los diferentes elementos que lo componen: sus instituciones (el CONACULTA, convertido aquí en CONAFOC, el Instituto de Artes y de Letras por el de Bellas Artes, revistas, periódicos etc.), sus rituales (presentaciones de libros, homenajes, recepciones), y sobre todo sus miembros.

El primero en abrirle los ojos a Evaristo es Roberto Lima durante su única conversación con él. Lima se lanza en una diatriba contra «el aparato cultural del estado» (Serna 2005: 38). Le explica como «los burócratas de la cultura» logran enriquecerse sacando provecho de las sinecuras de lujo, plazas de agregado cultural en el servicio exterior, etc. Consolidan así un sistema de corrupción a escala nacional que no dista mucho del que impera en la policía judicial. Y así, página tras página, se perfila con cada vez más precisión una 
especie de comedia humana en la que cada uno de los miembros convocados tiene un doble en el universo del hampa policial.

El personaje de Fabiola Nava por ejemplo, despampanante ex novia de Roberto Lima tiene como homóloga a Dora Elsa, la stripper de la que se enamora Evaristo. De buenas a primeras todo las opone: Fabiola es una hermosa y distinguida artista y escritora en ciernes, mientras que Dora Elsa es una prostituta ya madura que tiene que ingeniárselas con shows cada vez más atrevidos para no perder clientela. Sin embargo, resulta que Fabiola no le va a la zaga en cuestión de prostitución ya que es en realidad una especie de prostituta cultural dispuesta a vender cuerpo y alma para hacer que publiquen su libro. Añade pues a la prostitución física la prostitución moral. En cambio, Dora Elsa da muestras de mucha más nobleza de espíritu pues su amor por Evaristo es sincero, desinteresado y hasta acaba por sacrificarse por él.

Asimismo, los numerosos personajes de la Mafia intelectual que aparecen en la novela forman una especie de retrato en caleidoscopio del comandante Mayortena, como si cada uno representara uno de los defectos concentrados en el personaje del comandante. Tenemos, por ejemplo, al narco poeta Osiris Cantú, que logra publicar sus obras al convertirse en el camello personal de la intelligenstia; a Claudio Vilchis, el arribista lambiscón que ocupa un lugar importante en la jerarquía cultural gracias a sus relaciones; a Ignacio Carmona que obtuvo una cátedra muy lucrativa al presentar un recibo de alquiler escrito en alemán como diploma de doctorado de la universidad de Gotinga, etc. El personaje que más se parece al jefe de los policías, es el jefe, o la jefa en este caso, de los intelectuales, la secretaria del CONAFOC (o sea la Ministra de Cultura) Perla Tinoco. El paralelismo es más que claro cuando Evaristo, bajo el efecto conjugado el alcohol y de la droga, sufre una siniestra alucinación en la que una cucaracha y una rata, con las caras de Perla Tinoco y Mayortena, lo insultan y tratan de devorarlo.

Este episodio es uno de los ejemplos de las metáforas animales que esmaltan el relato y aclaran el título de la novela. La expresión «el miedo a los animales» aparece en el interior de la diégesis a través de una nota que el asesino deja a Evaristo. La nota dice así: «Date por muerto, pinche judicial de mierda. Ya sé donde vives y no le tengo miedo a los animales» (Serna 2005: 58). Aquí el asesino quiere asociar el término «animal»a los miembros de la judicial para estigmatizar su ignorancia crasa y su brutalidad, pero en la novela el lector se da cuenta de que la voz narrativa, ella también, asimila intelectuales y animales. Tenemos un ejemplo significativo en el 
pasaje en el que Evaristo está escondido en los almacenes del Instituto de Artes y de Letras, en los que se apilan los miles de libros editados por el gobierno y que nadie lee. Evaristo trata de dormir en medio de este "cementerio cultural», encima de las estanterías, pero lo atacan las ratas y tarántulas que pululan en el fondo de las cajas o entre las páginas de los libros. Esta es una perfecta metáfora del mundo cultural mexicano tal como está presentado en este libro: un cementerio infestado de bichos malignos.

Entre las figuras culturales que desfilan en el libro, se pueden reconocer algunos mascarones de proa de las letras mexicanas. Para dos personajes, Wenceslao Medina Chaires y Javier Loperena, parece que Serna se divirtió confundiendo las pistas al mezclar rasgos de varias de las figuras totémicas de la intelectualidad mexicana. Wenceslao Medina Chaires, leyenda de la intelectualidad democrática y progresista del periodo salinista puede hacer pensar en Carlos Monsiváis, pero el hecho de que estuvo encarcelado en Lecumberri en el 68, nos remite más a José Revueltas; Javier Loperena puede ser una mezcla entre Fernando del Paso que escribió una novela histórica sobre el general Santa Anna, y Carlos Montemayor por sus escritos sobre la guerrilla de Lucío Cabañas.

En cambio, el personaje de Palmira Jackson es claramente identificable. Se trata de una señora ya entrada en años, con un apellido de origen extranjero, nacida en una familia muy acomodada, quien, además de ser una eminencia intelectual nacional, por su valor político y su compromiso a favor de los más pobres, es uno de los iconos más estimados y entrañables del país. Resulta difícil ser más explícito y no ver el paralelismo con Elena Poniatowska, a la que Serna ataca con encarnizamiento en esta novela. Después de la larga sucesión de decepciones que constituyen el viaje de Evaristo por las altas esferas de la mente de su país, éste piensa que Palmira Jackson es su última esperanza. Mientras las pruebas lo condenan, está convencido de que esta gran justiciera sabrá escucharlo y salir en su defensa: "Creía en la Jackson como otros creen en la Biblia», nos dice el narrador (Serna 2005: 58). Por eso mismo va a ser su mayor decepción. Se da cuenta de que la Jackson es de la misma calaña que sus congéneres, e incluso peor: hipócrita, elitista, vanidosa, codiciosa, no es un animal, es un monstruo. Es el golpe de gracia para Evaristo, la mujer a la que veía como la encarnación de la Virgen de Guadalupe, «santa patrona de la izquierda mexicana» (219) es una miserable, un terrible animal, «un velocirráptor que sacaba espuma por la boca» (219), un monstruo como Mayortena. Con la imagen sagrada 
de Palmira Jackson, se esfuman lo que le quedaba de ilusiones sobre la intelligentsia que tanto admiraba antes.

Palmira Jackson es la representación máxima de la hipocresía, la más insoportable tara de la casta intelectual que se deja cegar por sus propias cortinas de palabras donde se labra su superioridad moral. El contraste es enorme entre el lenguaje público de los enardecidos desplegados, en los que Palmira Jackson afirma que «la palabra es nuestra única arma, un arma que usamos para darles voz a los sin rostro, a los sin tierra, a los olvidados de hoy y de siempre» (172), y el lenguaje mezquino de los corrillos íntimos, en que sólo prevalecen las honrillas personales.

En el triste retrato que pinta Serna de la clase intelectual mexicana, sólo el personaje de Roberto Lima salva el grupo entero del oprobio definitivo. Lima es un hombre puro, incorruptible y por eso mismo vivía al margen del sistema. Como lo explica uno de sus amigos: «El Robert era un tipazo, un espíritu libre que no le tenía medio a nada [...]. Vivió en el filo de la navaja porque nunca transigió con la miseria moral de este mundo, ni como escritor, ni como persona» (70).

Precisamente porque no se dejaba encasillar por sus valores hipócritas, el sistema lo eliminó. Serna ideó un asesinato bastante malicioso: Lima fue matado de un golpe en la nuca con un diccionario de sinónimos y contrarios. No se hubiera podido encontrar arma más adecuada por parte de un asesino letrado pero este detalle puede tener también otra signifación: revela que Lima fue matado por los suyos, sus sinónimos, que son también todo su opuesto, sus antónimos, sus contrarios.

\section{Evaristo: animal e intelectual}

Lima es el único representante de la casta cultural que vale más que su equivalente del poder judicial, es decir Evaristo. De hecho, Lima es todo lo que Evaristo no tuvo el valor de ser. Sin embargo, su muerte dará la oportunidad al protagonista de vencer a su otro alter ego, el asesino de Lima, Rubén Estrella. Rubén Estrella era muy amigo de Lima pero lo asesinó en un gesto de cólera cuando se enteró de que Lima lo había descartado de un congreso de escritores por falta de talento. A lo largo de su investigación, Evaristo se equivoca sobre su cuenta ya que Rubén parece otro Roberto Lima, su sinónimo, tan ajeno como él al hampa literaria. No obstante acaba descubriendo que Rubén es un animal brutal que mata por vanidad y es capaz de acusar a otro, en este caso a Evaristo, en su lugar. 
En cuanto a Evaristo, al final, podemos decir que está a medio camino entre Lima y Estrella. Queda todavía en él una parte de la inocencia inmaculada de Lima pero se sabe también habitado por la fuerza oscura de Estrella, que es la del poder animal. Además de su falta de valor por resistirse a los beneficios financieros de su trabajo como judicial, las pocas veces que tuvo la oportunidad de utilizar la fuerza que le conceden su posición y su arma, sintió como se dejaba embriagar:

recordó la grosteca sensación de poderío que había experimentado la mañana anterior mientras interrogaba al reportero de El Universal. La compulsión sádica de aplastar al débil, que tanto detestaba en la conducta de los judiciales, de pronto se reveló como un atributo de su carácter (60).

Evaristo es pues intelectual y animal a la vez, como todos los intelectuales del medio. Este descenso a su infierno personal, y al de la intelligentsia, le permitió darse cuenta de todo ello y por lo tanto renacer tal un nuevo Roberto Lima, íntegro, entero, sin ilusiones. Así, a pesar de la negrura panfletaria de esta novela, Serna nos concede un happy end, otra vez en clave simétrica.

Evaristo acaba por ser disculpado y reconocido por el medio cultural al ganar un premio por una novela-reportaje titulada Los sueños decapitados (en referencia a las Ilusiones perdidas de Balzac) que cuenta su historia. Evaristo escribe por fin este famoso reportaje con el que soñaba desde joven, pero para ello, tuvo que adentrarse no en los bajos fondos del mundo del poder sino en los bastidores del mundo del saber. En vez de seguir con una carrera literaria llena de promesas, prefiere ser reincorporado en la policía judicial. Si el libro se abría con un sueño de Evaristo en que, en la cumbre de la gloria literaria, daba entrevistas al lado de sus semejantes, la novela termina con una sentencia realista y desilusionada. A la pregunta de un periodista de por qué volver a la policía cuando tenía un sitio importante como escritor, Evaristo contesta:

- Por eso mismo - le respondió -. Necesitaba respirar aire puro.

En el medio cultural, su respuesta se tomó como una boutade de mal gusto. (269)

\section{Conclusión}

A pesar de la dimensión cómica y caricaturesca de la obra, El miedo a los animales no es una simple boutade. A través de este retrato incendiario del mundillo intelectual mexicano, Enrique Serna plantea la cuestión de 
los intelectuales frente al poder, no tanto de sus relaciones con el poder político como del poder que llegan a poseer y que los transforma en su peor enemigo, en intelectuales animales o animales intelectuales. Se puede concluir diciendo que Enrique Serna no le tiene miedo a los intelectuales y que sin duda el espejo deformante que les presenta el autor, y en el que se ve también autorretratado, es un sano ejercicio de autocrítica, aún más en un país como México en que los letrados siguen ocupando un lugar delicado en el debate público.

\section{Bibliografía}

Ollé-Laprune, Philippe, 2008, Mexique: Les visiteurs du rêve, Paris, Éd. de la Différence. Rodríguez Ledesma, Xavier, 2001, Escritores y poder, la dualidad republicana en México, 1968-1994, México, CONACULTA.

Serna, Enrique, 1996, Las caricaturas me hacen llorar, México, Joaquín Mortiz.

Serna, Enrique, 2005, El miedo a los animales, México, Joaquín Mortiz.

Volpi, Jorge, 2004, La guerra y las palabras, una historia intelectual de 1994, México, Era. 